\title{
Cardiovascular System Findings Supplemental Qualifiers Dataset
}

National Cancer Institute

\section{Source}

National Cancer Institute. Cardiovascular System Findings Supplemental Qualifiers

Dataset. NCI Thesaurus. Code C147195.

A dataset containing supplemental information, specifically non-standard variables, to parent records in the cardiovascular system findings domain. 